\title{
Pengaruh Senam Yoga Terhadap Penurunan Nyeri Haid Pada Remaja Putri Di Institut Kesehatan Mitra Bunda
}

\author{
Desi Ernita Amru1, Anisya Selvia² \\ 1,2 Institut Kesehatan Mitra Bunda, Batam, Indonesia
}

\begin{abstract}
A B S T R A C T
Adolescence is marked by changes in body development associated with puberty. In this condition, women will experience ovulation and menstruation which is sometimes accompanied by menstrual pain (dysmenorrhea). This condition can get worse when accompanied by unstable psychological conditions, such as stress, depression, excessive anxiety, and excessive sadness or joy. The purpose of this study was to determine the effect of yoga exercise on reducing menstrual pain in adolescent at the Mitra Bunda Health Institute. The type of this research is preexperimental with one group pretest posttest design. The population of this study was all students of the Midwifery Undergraduate Study Program at the Mitra Bunda Health Institute with a total of 75 students. The sample of this study was 75 female students with a total sampling technique. The independent variable is Yoga Gymnastics and the dependent variable is Menstrual Pain. The research instrument uses the Face Pain Scale - Revised (FPS-R) pain scale measurement. Data processing using editing, coding, scoring, tabulating with data analysis Spearman Rank. The results showed that before doing yoga exercise there were 46 respondents (61.3\%) experiencing menstrual pain on a scale of 3 (more painful), while after yoga exercise there were 30 respondents $(40 \%)$ experiencing menstrual pain on a scale of 1 (slight pain). Spearman rank statistical test shows that $P$ value $=0,000<\alpha(0,05)$. So that Hypothesis 1 is accepted, it means that there is an effect of yoga exercise on reducing menstrual pain in adolescent girls at the Mitra Bunda Health Institute, Batam. Suggestions for respondents are expected to get used to doing yoga to reduce menstrual pain so as not to depend on analgesic drugs every menstruation
\end{abstract}

Keywords : adolescent; dysmenorrhea; yoga exercise

\section{ARTICLE INFO \\ Article history}

Received : 8 January 2022

Revised : 31 January 2022

Accepted : 31 January 2022

\section{DOI}

DOI : 10.31983/micajo.v3i1.8188

\section{CORRESPONDING AUTHOR}

$\begin{array}{llll}\text { Name } & : & \text { Desi Ernita Amru } \\ \text { Email } & : & \text { dhesyamru@yahoo.co.id } \\ \text { Telp } & : & 081990978397 \\ \text { Address } & : & \text { Institut Kesehatan Mitra } \\ & & \text { Bunda Jl. Seraya no.1 } \\ & \text { Kota Batam }\end{array}$

ORIGINAL RESEARCH

\section{Pendahuluan}

Masa remaja merupakan suatu proses transisi dari masa anak- anak menuju tahap dewasa yang ditandai dengan berubahnya perkembangan tubuh yang cepat. Masa remaja berhubungan dengan suatu fenomena fisik yang berhubungan dengan pubertas. Pada saat ini perempuan akan mengalami ovulasi dan menstruasi yang terkadang juga disertai nyeri haid (dysmenorrhea). Kondisi ini dapat bertambah parah bila disertai dengan kondisi psikis yang tidak stabil, seperti stres, depresi, cemas berlebihan, dan keadaan sedih atau gembira yang berlebihan (Anurogo, D., \& Wulandari, 2017).

Menurut World Health Organization (WHO) tahun 2016 didapatkan 1.769 .425 jiwa (90\%) wanita di dunia mengalami dismenorea berat (Herawati, 2017). Angka kejadian dismenorea di Amerika serikat 30\% - 50\% perempuan usia reproduksi. Sekitar 10\% - 15\% diantaranya terpaksa kehilangan kesempatan kerja, sekolah, dan kehidupan keluarga. Swedia ditemukan angka kejadian dismenorea pada wanita berumur 19 tahun sebanyak $72,42 \%$ (Adzkia, 2020). Menurut hasil penelitian Singh et al (2011), sekitar 8,86\% remaja 
yang mengalami dismenorea primer berat tidak hadir di sekolah dan sebanyak $67,08 \%$ remaja menarik diri dari kegiatan sosial, akademik, dan olahraga (Das, A. P., \& Singh, 2011).

Angka kejadian (prevalensi) nyeri menstruasi berkisar 45 - 95\% di kalangan wanita usia produktif (Agustini et al., 2019). Di Batam jumlah remaja putri yang mengalami dismenore dan datang ke bagian kebidanan sebesar 11.565 jiwa (1,31\%). Menurut penelitian yang dilakukan oleh Sri Mudayatiningsih, dkk dalam jurnalnya pada tahun 2017 di SMAN 7 Malang, Jawa Timur terdapat 35 siswi yang sedang menstruasi mengalami dysmenorrhea ringan sebanyak 9 siswi (25,7\%), 14 siswi (40,0\%) mengalami dysmenorrhea sedang, dysmenorrhea berat sebanyak 10 siswi $(28,6 \%)$ dan hanya 2 siswi $(5,7 \%)$ yang tidak merasakan nyeri haid (Irmayanti, 2017).

Hasil studi pendahuluan di Institut Kesehatan Kota Batam yang dilakukan oleh peneliti tanggal 10-15 Maret 2020 didapatkan hasil wawancara dari 48 mahasiswi, terdapat 32 mahasiswi yang mengalami nyeri saat menstruasi (dysmenorrhea). Responden yang mengalami dysmenorrhea melakukan penanganan dengan beberapa cara, diantaranya menggunakan minyak kayu putih sebanyak 16 responden $(46,1 \%)$, dengan cara istirahat 2 responden (15,4\%), dengan mengkonsumsi minuman herbal 2 responden $(15,4 \%)$ dan tidak pernah melakukan penanganan dismenore 12 responden $(23.1 \%)$.

Gangguan ini tidak boleh didiamkan, dampak yang terjadi jika nyeri haid (dysmenorrhea) tidak ditangani adalah gangguan aktifitas hidup sehari-hari, gelisah, depresi, Retrograd menstruasi (menstruasi yang bergerak mundur), infertilitas (kemandulan), ektopik pecah, dan kista pecah (dysmenorrhea) (Irianto, 2014)

Upaya yang dilakukan untuk mengurangi rasa nyeri yang dirasakan saat menstruasi seperti mengkonsumsi minuman herbal (jamu), istirahat, kompres hangat, bahkan beberapa diantara remaja juga mengkonsumsi obat agar mereka tetap bisa melakukan aktifitas seharihari. Pengaruh nonfarmakologis juga diperlukan untuk mengurangi dysmenorrhea, salah satunya dengan menggunakan teknik relaksasi, olah raga dan yoga (Sulistyo Andarmoyo, 2013).

Yoga merupakan tehnik yang mengajarkan seperti tehnik relaksasi, pernafasan, dan posisi tubuh untuk meningkatkan kekuatan, keseimbangan dan mengurangi rasa nyeri (Sindhu, 2014). Frekuensi latihan yoga dapat dilakukan 10-15 menit atau sebanyak dua kali dalam sepuluh hitungan, sambil mengatur nafas dalam (Maryam, 2018).

Tujuan penelitian ini untuk mengetahui pengaruh senam yoga terhadap pengurangan nyeri haid pada remaja putri di Institut Kesehatan Mitra Bunda.

Naskah ditulis dalam font Arial ukuran 11 pt baik pada pendahuluan maupun bab - bab seterusnya dengan indentasi $1 \mathrm{~cm}$ di sebelah kiri. Paragraf diketik dengan rata kanan dan kiri. Spasi yang dipergunakan adalah 1,15. Pendahuluan memaparkan tentang latar belakang penelitian yang dilakukan. State of the art dalam penelitian yang menjadi dasar dalam penelitian ilmiah. Pada kajian literatur review juga memaparkan pentingnya literatur review tersebut dilakukan, masalah yang terjadi sehingga dilakukan literatur review. Author tidak diperkenankan melakukan duplikasi atau repetisi penjelasan yang sudah dipublikasikan. Spasi antara akhir kalimat dengan bab selanjutnya adalah 1,5.

\section{Metode}

Jenis penelitian adalah pra eksperimental dengan rancangan one group pretest posttest design (Sugiono, 2017). Populasi penelitian ini adalah seluruh seluruh mahasiswa Prodi Sarjana Kebidanan di Institut Kesehatan Mitra Bunda sejumlah 75 mahasiswi. Sampel penelitian ini sejumlah 75 mahasiswi dengan tekhnik total Sampling. Variablel independent adalah Senam Yoga dan variable dependent adalah Nyeri Haid. 
Instrumen yang digunakan dalam penelitian yaitu standar operasional prosedur (SOP) senam yoga dan menggunakan pengukuran skala nyeri Face Pain Scale-Revised (FPS-R). Pengolahan data menggunakan editing, coding, scoring, tabulating dengan analisa data spearman Rank.

Pengambilan data yoga dilakukan sebanyak $2 x$ via zoom dikarenakan penelitian ini dilakukan disaat masa pandemi. Peneliti melakukan evaluasi apakah pada saat zoom responden memahami dan bisa melakukan teknik yoga dengan melakukan latihan secara langsung dan terbatas. Sejumlah 75 sampel dibagi menjadi 9 kelompok kecil, pertemuan secara langsung 9 kali dengan durasi 45 menit/kelompok. Jadwal pertemuan 1 hari hanya 2 kelompok, pagi pukul 09.00-09.45 Waktu Indonesia Barat (WIB) dan siang pukul 14.00-14.45 WIB sehingga setiap kelompok tidak bertemu.

\section{Hasil dan Pembahasan}

Tabel 1 Karakteristik Responden Berdasarkan Umur, Usia Pertama Menarch, Lama Menstruasi, Waktu Timbulnya Nyeri pada Remaja Putri Institut Kesehatan Mitra Bunda Batam Tahun 2021

\begin{tabular}{|c|c|c|c|}
\hline No & Kategori & $\mathbf{N}$ & $\%$ \\
\hline \multicolumn{4}{|c|}{ Kategori Remaja } \\
\hline 1 & Remaja Tengah & 7 & 9,3 \\
\hline 2 & Remaja Akhir & 68 & 90,7 \\
\hline & Total & 75 & 100 \\
\hline \multicolumn{4}{|c|}{ Usia Menarche } \\
\hline 1 & $11-12$ tahun & 9 & 12 \\
\hline 2 & 13 tahun & 64 & 85,3 \\
\hline 3 & $14-15$ tahun & 2 & 2,7 \\
\hline & Total & 75 & 100 \\
\hline \multicolumn{4}{|c|}{ Lama Menstruasi } \\
\hline 1 & $<4$ hari & 0 & 0 \\
\hline 2 & $4-7$ hari & 59 & 78,7 \\
\hline 3 & $>7$ hari & 16 & 21,3 \\
\hline & Total & 75 & 100 \\
\hline \multicolumn{4}{|c|}{ Waktu Timbulnya Nyeri Haid } \\
\hline 1 & Sebelum Haid & 19 & 25,3 \\
\hline 2 & Hari ke $1 \& 2$ Haid & 56 & 74,7 \\
\hline 3 & Hari ke 1 - haid selesai & 0 & 0 \\
\hline \multicolumn{2}{|r|}{ Total } & 75 & 100 \\
\hline
\end{tabular}

Tabel 2 Distribusi Frekuensi Nyeri Haid Sebelum Dan Setelah Dilakukan Tindakan Senam Yoga Pada Remaja Putri Institut Kesehatan Mitra Bunda Batam Tahun 2021

\begin{tabular}{|c|c|c|c|}
\hline No & Skala Nyeri & $\mathbf{N}$ & $\%$ \\
\hline \multicolumn{4}{|c|}{ Sebelum Senam Yoga } \\
\hline 1 & 0 (tidak nyeri) & 0 & 0 \\
\hline 2 & 1 (sedikit nyeri) & 0 & 0 \\
\hline 3 & 2 (sedikit lebih nyeri) & 16 & 21,3 \\
\hline 4 & 3 (lebih nyeri) & 46 & 61,4 \\
\hline 5 & 4 (sangat nyeri) & 12 & 16 \\
\hline 6 & 5 (nyeri sangat hebat) & 1 & 1,3 \\
\hline \multicolumn{2}{|r|}{ Total } & 75 & 100 \\
\hline \multicolumn{4}{|c|}{ Setelah Senam Yoga } \\
\hline 1 & 0 (tidak nyeri) & 17 & 27,7 \\
\hline 2 & 1 (sedikit nyeri) & 30 & 40 \\
\hline 3 & 2 (sedikit lebih nyeri) & 19 & 25,3 \\
\hline 4 & 3 (lebih nyeri) & 9 & 12 \\
\hline 5 & 4 (sangat nyeri) & 0 & 0 \\
\hline 6 & 5 (nyeri sangat hebat) & 0 & 0 \\
\hline \multicolumn{2}{|r|}{ Total } & 75 & 100 \\
\hline
\end{tabular}

Tabel 3 Uji Paired Samples Test Pengaruh Senam Yoga Terhadap Penurunan Nyeri Haid Pada Remaja 
Putri Institut Kesehatan Mitra Bunda Batam Tahun 2021

\begin{tabular}{lccc}
\hline \multicolumn{1}{c}{ Variabel } & t-hitung & Sig. & Level of Significant \\
\hline Pre-test dan Post-test & 11,533 & 0,000 & 0,05 \\
\hline $\mathrm{n}=75$ & & & \\
\hline
\end{tabular}

\section{Nyeri Haid sebelum dilakukan Senam Yoga pada Remaja Putri}

Tabel 2 menunjukkan bahwa nyeri haid sebelum dilakukan tindakan Senam Yoga pada remaja putri dengan jumlah 75 responden, sebagian besar responden yang mengalami nyeri haid dengan skala 3 (lebih nyeri) dengan jumlah 46 responden $(61,3 \%)$.

Nyeri Haid (Dysmenorrhea) adalah nyeri perut yang berasal dari kram yang terjadi selama menstruasi. Disebut dysmenorrhea primer jika tidak ditemukan penyebab yang mendasarinya dan dismenorea sekunder jika penyebanya adalah kelainan kandungan (Manuaba, IBG, 2013).

Menurut peneliti nyeri yang dialami remaja putri dapat berkaitan dengan umur dan waktu haid pertama (menarche) remaja. Nyeri haid biasanya tidak muncul pada awal remaja mengalami menarche dan seiring remaja bertambah dewasa, biasanya nyeri haid yang dirasakan mulai berkurang.

Berdasarkan tabel 1 menunjukkan bahwa sebagian besar dari responden berada pada kategori remaja akhir sebanyak 68 responden $(90,7 \%)$ dan menunjukkan bahwa sebagian besar dari responden mengalami menarche di usia 13 tahun yaitu sebanyak 64 responden $(85,3 \%)$.

Nyeri Haid (Dysmenorrhea) kemungkinan terjadi 2-3 tahun setelah menstruasi pertama (Manuaba, 2009). Menururt peneliti, nyeri yang dialami oleh remaja putri Institut Kesehatan Mitra Bunda merupakan suatu hal yang semestinya terjadi pada remaja (berusia 16 tahun), karena jika remaja mengalami haid pertama kali (menarche) pada usia 13 tahun, nyeri haid dapat terjadi 2 - 3 tahun setelahnya yaitu pada usia 16 tahun. Sebagian besar remaja putri Institut Kesehatan Mitra Bunda mengalami nyeri haid yang timbul 1-2 hari pad saat haid yaitu sebanyak 56 responden (74,7\%).

Nyeri haid dapat di tandai dengan gajala seperti kram pada perut bagian bawah dan nyeri punggung. Nyeri mulai timbul sesaat sesudah atau selama haid, mencapai puncaknya dalam waktu 24 jam dan setelah 2 hari akan menghilang. Dysmenorrhea juga sering disertai dengan sakit kepala, mual, sembelit atau diare, mudah tersinggung dan sering berkemih, dan kadang sampai menjadi muntah (Sarwono, 2017).

Menurut peneliti, hal itu merupakan suatu keadaan yang fisiologis bagi remaja putri yang mengalami nyeri pada saat menstruasi. Karena pada saat itu, kadar estrogen dalam tubuh berada pada titik terendah. Sedangkan hormone prostaglandin (berperan memicu kontraksi rahim agar lapisan rahim terkikis dan dikeluarkan melalui darah menstruasi) semakin meningkat.

\section{Nyeri Haid setelah dilakukan Senam Yoga pada Remaja Putri}

Berdasarkan tabel 2 menunjukkan bahwa nyeri haid setelah dilakukan Senam Yoga pada remaja putri Institut Kesehatan Mitra Bunda pada 75 responden, hampir dari setengah responden mengalami nyeri haid dengan skala 1 (sedikit nyeri) sebanyak 30 responden $(40 \%)$.

Senam Yoga Saat Menstruasi merupakan latihan yang terdiri dari gerakan fisik, pernafasan dalam, dan meditasi untuk meringankan masalah yang muncul saat menstruasi. Posisi yoga yang dilakukan saat sedang menstruasi terdiri dari posisi yang merilekskan tubuh dengan metode pernafassan yang dapat membuat kondisi mental menjadi jauh lebih baik. 
Posisi yoga untuk menstruasi dapat memberikan kekuatan dan menstimulasi otak, dada, paruparu dan hati, serta dapat mempertahankan keseimbangan hormon dalam tubuh (Lebang, 2016).

Menurut peneliti senam yoga dapat mengurangi nyeri haid karena gerakan - gerakan yang dilakukan dalam senam yoga saat menstruasi adalah gerakan yang dapat meregangkan bagian pinggul, tulang punggung, melancarkan sistem pencernaan, merileskskan organorgan dalam perut dan membantu mempertahankan keseimbangan hormone.

\section{Pengaruh Senam Yoga terhadap Nyeri Haid pada Remaja Putri}

Nyeri Haid pada remaja putri Institut Kesehatan Mitra Bunda dengan jumlah 75 responden menunjukkan bahwa hampir setengahnya dari responden mengalami penurunan nyeri haid setelah dilakukan Senam yoga yaitu 48,3\% atau sebanyak 37 responden, dengan nyeri sebelum senam yoga menurut FPS-R nomor 3 (lebih nyeri) dan setelah dilakukan senam yoga dengan nyeri menurut FPS-R nomor 1 (sedikit nyeri).

Beberapa gerakan yoga saat menstruasi dapat mengurangi nyeri haid bila gerakan dilakukan dengan tepat, karena gerakan - gerakan dalam yoga saat menstruasi dapat memberikan kekuatan dan menstimulasi otak, dada, paru-paru dan hati, serta dapat mempertahankan keseimbangan hormon dalam tubuh.

Berdasarkan data di atas dan menurut uji statistik Spearman Rank dengan bantuan program SPSS pada taraf kesalahan 5\% dilakukan perhitungan untuk mengetahui ada tidaknya pengaruh antara variabel yaitu variabel bebas dan variabel terikat. Hasil dari perhitungan adalah $0,000<\alpha(0,05)$. Hal ini menunjukkan bahwa 0,000 lebih kecil dari 0,05 (Nursalam, 2016). Dengan demikian H0 yang menyatakan tidak ada pengaruh senam yoga terhadap nyeri haid pada remaja putri ditolak dan $\mathrm{H} 1$ diterima. Jadi kesimpulannya terdapat pengaruh senam yoga terhadap nyeri haid pada remaja putri Institut Kesehatan Mitra Bunda. Senam Yoga Saat Menstruasi merupakan latihan yang terdiri dari gerakan fisik, pernafasan dalam, dan meditasi untuk meringankan masalah yang muncul saat menstruasi. Posisi yoga yang dilakukan saat sedang menstruasi terdiri dari posisi yang merilekskan tubuh dengan metode pernafassan yang dapat membuat kondisi mental menjadi jauh lebih baik. Posisi yoga untuk menstruasi dapat memberikan kekuatan dan menstimulasi otak, dada, paru-paru dan hati, serta dapat mempertahankan keseimbangan hormon dalam tubuh.

Yoga akan menambah kelenturan tubuh secara aman, karena latihannya ringan sehingga membuat tubuh terhindar dari kekakuan, tekanan, nyeri, dan kelelahan. Yoga juga meningkatkan "pelumas" dan kinerja dari persendian. Hasilnya adalah pergerakan darah dan kinerja organ tubuh akan terasa nyaman dan lancar. Yoga menarik seluruh otot secara ringan, mulai dari ligament, tendon, dan lain-lain yang mengelilingi otot sehingga otot akan semakin lentur.

Menurut penelitian Dewi Sekarsari dan Arini Darmayanti (2015) tentang Pengaruh Yoga terhadap Berkurangnya Nyeri Haid (Dysmenorrhea) pada Remaja Putri Kelas IX di SMPN 3 Madiun tahun 2015. Hasil penelitian menunjukkan bahwa sebelum dilakukan Yoga sebagian remaja mengalami nyeri berat dan berkurang menjadi nyeri sedang setelah dilakukan senam yoga. Hasil uji Wilxocon sigh rank test $\alpha=0,05$ menunjukkan $p=0,001$ sehingga $p<0,05$ artinya ada pengaruh Yoga terhadap penurunan intensitas nyeri Haid. Menurut peneliti, Yoga merupakan alat terapi yang paling tepat untuk mengatasi nyeri saat menstruasi karena gerakan yang dilakukan saat Yoga pada waktu menstruasi merupakan posisi yang dapat merilekskan organ bagian dalam perut termasuk organ reproduksi. Yoga juga dapat dilakukan oleh remaja dalam aktifitas sehari - hari, sehingga saat menstruasi dan saat nyeri haid timbul, remaja tidak perlu mengkonsumsi obat analgesic untuk mengurangi 
nyeri tersebut. Hal ini membantu remaja putri untuk menghindari ketergantungan mengkonsumsi obat analgesic saat menstruasi.

\section{Simpulan}

Dari penelitian ini dapat disimpulkan bahwa Senam Yoga terbukti efektif menurunkan nyeri haid pada remaja putri. Hal ini dilihat dari sebelum senam Yoga level 3 (lebih nyeri) menjadi level 1 (sedikit nyeri) setelah senam yoga.

\section{Daftar Pustaka}

Adzkia, M. (2020). Hipnoterapi Untuk Menurunkan Nyeri Disminore. Real in Nursing Journal, 3(2), 115-122.

Agustini, R., Puspitasari, E., \& Listyaningrum, T. H. (2019). Hubungan Usia Menarche Dengan Kejadian Dismenore Pada Siswi Kelas Viii Smpn 3 Gamping Yogyakarta Tahun 2019.

Anurogo, D., \& Wulandari, A. (2017). Cara Jitu Mengatasi Nyeri Haid. ANDI.

Das, A. P., \& Singh, S. (2011). Occupational health assessment of chromite toxicity among Indian miners. Indian Journal of Occupational and Environmental Medicine,.

Herawati, R. (2017). Faktor-Faktor Yang Mempengaruhi Kejadian Nyeri Haid (Dismenorea) Pada Siswi Madrasah Aliyah Negeri Pasir Pengaraian. DIII Kebidanan UPP, 161-172.

Irianto, K. (2014). Panduan Lengkap Biologi Reproduksi Manusia Human Reproductive .Biology untuk Paramedis dan Nonparamedis. Alfabeta.

Irmayanti, D. A. (2017). Pengaruh Senam Aerobik Terhadap Tingkat Stres pada Remaja Putri di Madrasah Aliyah Negeri I Yogyakarta.

Lebang, E. (2016). Food Combining \& Yoga Mengendalikan Stress. PT. Mizan Pustaka.

Manuaba, IBG, D. (2013). IImu Kebidanan Penyakit Kandungan dan KB. EGC.

Maryam, S. F. (2018). Mengenal usia lanjut dan perawatannya. Salemba Medika.

Nursalam. (2016). Metodologi Penelitian IImu Keperawatan Pendekatan Praktis. Salemba Medika.

Sarwono. (2017). Ilmu Kebidanan. PT Bina Pustaka.

Sindhu, P. (2014). Panduan Lengkap Yoga untuk Hidup Sehat dan Seimbang. PT Mizan Pustaka.

Sugiono. (2017). Metodologi Penelitian. Alfabeta.

Sulistyo Andarmoyo. (2013). Konsep Dasar Keperawatan. (E. A. Mardella, Ed.). ar-ruzz Media. 